\title{
The Effect of Treatment Motivation Levels on Patients Sent to a Conditional Substance Abuse Treatment Program*
}

\section{Efecto de los niveles de motivación al tratamiento en pacientes enviados a un programa de tratamiento de abuso de sustancias condicional}

\author{
Sefa Bulut ${ }^{\mathrm{a}}$ \\ Íbn Haldun University, Turquía \\ ORCID: http://orcid.org/0000-0002-2622-4390 \\ ÍLHAN BOZKURT \\ Sakarya University Traning and Reserach Hospital, \\ Turquía \\ ORCID: http://orcid.org/0000-0002-9939-8121
}

\begin{tabular}{lll}
\hline a Correspondence & author. & Email: \\
sefabulut22@gmail.com & &
\end{tabular}

How to cite: Bulut, S., \& Bozkurt, Í. (2019). The effect of treatment motivation levels on patients sent to a conditional substance abuse treatment program. Universitas Psychologica, 18(1), 1-16. https://doi.org/1 0.11144/Javeriana.upsy18-1.etml

\begin{abstract}
The main purpose of this study is to examine the effect of treatment motivation levels on substance abuse behaviors of patients sent to a substance dependence treatment program based on the decision of Supervised Release made during a six-week psycho-educational group treatment program. The sample consisted of 112 participants who applied to the Ministry of Health Turkey, Sakarya University Training and Research Hospital, Psychiatry Clinic between the years 20122014, and were selected among patients who attended a six-week treatment program. The Treatment Motivation Questionnaire (TMQ), Demographic Information Questionnaire and interview methods were used in data collection. Patients with high treatment motivation levels were found to have a low substance abuse rate, and their adaptation to the treatment program was high. Patients who had high motivation levels at the beginning of the treatment, had low rates of substance abuse at the end of the treatment. This trend was confirmed for all of the measured four sub-types of motivation.
\end{abstract}

Keywords

Treatment motivation; substance abuse; dependence; probation; psycho-educational groups.

\section{RESUMEN}

El propósito principal de este estudio es examinar el efecto de los niveles de motivación al tratamiento en los comportamientos de abuso de sustancias de los pacientes enviados a un programa de tratamiento de dependencia de sustancias basado en la decisión de alta supervisada tomada durante un programa de tratamiento psicoeducativo grupal de seis semanas. La muestra fueron 112 participantes que se presentaron al Ministerio de Salud de Turquía del Hospital de Capacitación e Investigación de la Universidad de Sakarya, Clínica de Psiquiatría entre los años 2012-2014, y fueron seleccionados entre los pacientes que asistieron a un programa de tratamiento de seis semanas. El Cuestionario 
de Motivación al Tratamiento (TMQ), el Cuestionario de información demográfica y los métodos de entrevista se utilizaron en la recolección de datos. Los pacientes con altos niveles de motivación para el tratamiento presentaron una tasa baja de abuso de sustancias y su adaptación al programa de tratamiento fue alta. Los pacientes que tuvieron altos niveles de motivación al inicio del tratamiento, presentaron bajas tasas de abuso de sustancias al final del mismo, esta tendencia fue confirmada para todos los cuatro sub-tipos de motivación medidos.

Palabras clave

motivación al tratamiento; abuso de sustancias; dependencia; periodo de prueba; grupos psicoeducativos.

Substance dependence is a multifaceted problem that affects the whole society. Thus, in recent years practitioners and researchers are increasingly interested in understanding the substance abuse treatment process and factors that affect treatment motivation (Simoneau \& Bergeron, 2003). The current situation of patients should be well known to provide adaptation and create behavioral changes among patients (Fernandez-Montalvo, LopezGoni, Arteaga, \& Cacho, 2013). Studies regarding traditional behavior modification approaches are mostly conducted by ignoring the individual's current stage of change or considering patients when they are ready for behavior modification. Individuals should attempt to keep their current stage of change to make it easier to prove their soberness. Psychological attempts applied regardless of the individual's level of readiness can cause the individual to develop resistance to change (Erol \& Erdoğan, 2007).

Dropouts represent a significant problem in psychotherapy, substance abuse treatment and all healthcare systems. Therefore, the exploration and the understanding of the underlying dimensions of motivational dynamics can open new windows for designing new treatment models which attempt improving motivation and keeping clients in treatment (Ryan, Plant \& O’Malley, 1995).

Similarly, Prochaska and DiClemente (1986) proposed a five-stage dynamic model: unaware, considering change, deciding to change, involving treatment and maintaining sobriety. More recent theories elaborated in providing full stages covering pre and in-treatments.

There are some studies which mention natural recovery or self-help for change which takes place without the formal help of others. Other natural recovery programs are AA, Self-management and Recovery Training, and rational emotive therapy which are not considered formal treatment programs (Sobell \& Sobell, 2000). Ryan, Plant and O'Malley's (1995) study shows that when patients autonomously participate in treatment, they stay in treatment longer. Similarly, when they see their clinicians being more supportive of autonomy, they also tend to stay longer.

Treatment motivation is an important factor in the substance abuser's readiness for treatment and treatment success (Cahill, Adinoff, Hosig, Muller \& Pulliam, 2003). Treatment motivation, defined as the ability to accept and be ready for change, can vary depending on the time and situation. According to existing research, a lack of treatment motivation results in feeling unready for the treatment, a low level of participation in the treatment, and a higher chance of dropping out of the treatment (Evren et al., 2006). Patients' approval for treatment does not mean they are ready for change (Evren, Dalbudak, \& Çakmak, 2008), especially if the patients agreed to receive the treatment because of a fear of punishment while they were on trial.

Referral sources are either legally mandated (by legal procedures) or formally mandated (by employers and other health and social services). Reasons for seeking treatment are more important in predicting treatment engagement than external pressures. A client's perception of the benefits and costs of treatment is considered very detrimental (Wild, Cunningham \& Ryan, 2006). As mentioned above, the treatment motivation is essential for the treatment's success (Savaşan, 2010). Readiness to change is not accepted as a characteristic of the client but as a product of interpersonal relations at the motivational interviews to increase treatment motivation. Resistance to therapy and denial of problems are not evaluated as characteristics of the client but as feedback to the expert's 
approach (Özdemir \& Taşc1, 2013). First, treatment motivation levels must be detected, and low motivation levels must be improved to increase the chance of the treatment's success in patients sent by a court order. In readiness of treatment and change, the persons believe about their controls also important, how they perceive their disease as a fixed aspect of their personality or as a changeable trait of personality. This model proposes a permanent trait which stays with a person for the rest of their lives. This notion negatively affects treatment success by reducing patient's expectations and motivations (Ryan et al., 1995). In treatment facilities, a client's motivation is underestimated or overestimated. Therefore, it is very imperative to assess a client's initial readiness and reasons for help-seeking behavior. A composite assessment of both for change, needs and reasons for help-seeking. This will give a clearer picture of clients' needs and treatment protocols (Freyer et al., 2005).

Deci and Ryan (1985) proposed selfdetermination theory in order to understand individual s' motivation. They defined intrinsic, extrinsic and A-motivation types. Individuals intrinsically motivated use their inner energy and do it for the sake of doing it. On the other hand, extrinsically motivated people hope to gain something. A-motivation types are also acting but not knowing why. Besides that, there are other researchers proposed other motivation models.

Ryan et al. (1995) identified three types of motivation: external motivation, interjected motivation (a mixture of internal conflict and quilt) and identified motivation (setting personal goals). Later, Wild, Cunningham and Ryan (2006) study involving factor analysis confirmed the earlier study. Treatment motivation yielded external motivation, interjected motivation and identified motivation.

Individuals who are internally motivated for treatment are willing to engage in with others and treatment programs actively. Therefore, patients with high levels of internalized motivation are more likely to stay in treatment and complete it. "Common wisdom" of Alcoholics Anonymous is that alcoholics must "hit bottom" before they seriously consider treatment. Those individuals manifest anxiety, depression and other emotional distress while they are "hitting bottom".

On the other hand, Miller (1999) proposed; recognition, ambivalence, and taking steps as a three level for motivation to change. Patients recognize their own problems will engage in behavioral change. However, in practice, this not always happens. For this happen, clients should believe that change is essential for themselves and possible. An internal commitment to change is a more important factor than formal attendance. Therefore, treatment goals should focus on internal beliefs, self-efficacy and clients' needs. Both clients' needs and goals should go together with treatment facilities targets. Precautions to prevent substance abuse and treatment approach models vary worldwide (Çiftçi \& Uluocak, 2010). In many countries, instead of a prison sentence, people arrested for drug possession or use are given Supervised Release (conditional probation) and treatment options (Altıntoprak, Akgür, Kitapçığlu, Yüncü, \& Coşkunel, 2014). In Turkey, since 1933, substance abusers have been given treatmentbased caution practice (supervised probation), which became treatment-based control as a more contemporary measure (Yavuz, 2012). Since 2006, Supervised Release Caution can be implemented for drug-related crimes, allowing patients who complete the treatment successfully to go unpunished. This treatment and follow-up process starting with a judicial decision is called "Supervised Release."

The SAMBA program, which was developed in 2006, is mostly used in cases of Supervised Release. In 2011, a pilot study about the effectiveness of this program was conducted with a group of prisoners who were alcohol and drug dependent (Ögel, Koç, Aksoy, \& Yorohan, 2011). However, the findings were insufficient for making interpretations about the efficiency of the program. There are no research findings in the literature about the effectiveness of SAMBA on patients on Supervised Release and AMATEM; thus, it is a critical oversight in the literature, especially as the program was 
developed nine years ago and commonly used by public institutions nowadays. The efficiency of this program should be tested not only by developers of the program but also by the other researchers and clinicians.

According to the SAMBA implementation guide, the SAMBA program can be applied not only by psychiatrists and psychologists but also by health officers and nurses (Ögel, et al., 2011). This opinion was included in The Ministry of Health of Turkey Circular published in 2015 Sağlık Bakanlı̆̆1, 2015). Even if the program is a structured program, clinicians including psychiatrists and psychologists, who are trained in psychopathology and have a license for psychotherapy, should be involved, as they can answer patients' questions correctly and make effective therapeutic decisions. Another critical problem is that this program does not provide education for the parents of the patient/ substance's abuser. These deficiencies could result in an investigation into the program and the judicial process if patients are punished because of the failure to complete the treatment successfully.

Treatment settings and therapist can both affect motivation. When therapists face unmotivated clients, they still can have an influence on clients' motivation. Researchers have mentioned treatment environment, perceived utility, characteristics of the therapist, social support and motives for help-seeking (Simoneau \& Bergeron, 2003). Similarly, Miller (1999) believed in the power of therapist and treatment center. Those two agents have significant power in the motivation of the client. Talking about client's problems and helping them goal settings strengthens the client's motivation. A therapist can emphasize clients' strengths, encourage small success and rewards and any positive changes. It is also important to note the fluctuation nature of motivation. Clients may need advice and help with developing realistic goals, for that to be achieved, every small success needs to be reconsidered, and future goals also be planned.

Drug addicts receive free out-patient or inpatient treatment at the treatment centers located in certain public hospitals. According to SAMBA KDS at the psycho-education group program, the SAMBA treatment program is held at clinics with more sessions. If these patients fail the treatment at the AMATEM, they are sentenced to prison or punished with a pecuniary penalty. If they complete the treatment successfully, they avoid punishment, providing they agree not to use any substances for five years.

Savaşan (2010) conducted a study about treatment motivation levels of substance abusers in Turkey. This study was conducted with alcohol/drug addicted inpatients to indicate the effect of the service environment on treatment motivation. Moreover, Evren et al. (2006) conducted an adaptation study for the TMQ developed by Ryan et al. (1995). However, research detecting the treatment motivation levels of patients sent for treatment according to the requirements of Supervised Release is lacking.

As seen in clinical practice, substance and drug abusers choose to participate in treatment to avoid a prison sentence. However, it is unclear whether they choose the treatment with the aim of recovering or to merely avoid the impending punishment; short and long-term results of treatment initiated by the external motivation of a court order area cause for real concern.

\section{Purpose and Importance of the Research}

As substance abuse and related crimes result in critical social and economic consequences (McCollister et al., 2014), the prevention of substance abuse and reintegration of drug addicts to society are critically important for public health and safety (Friedmann et al., 2012). The main purpose of this study is to detect the treatment motivation levels of patients sent to treatment based on the requirements of Supervised Release and to research the effect of treatment motivation levels on substance abuse during the treatment program. The basic criterion for participant failure is continuing to use drugs. Thus, it is important to find out the 
factors that affect substance abuse during this process.

This study examines separately the participants' levels of internal and external treatment motivation at the start-up phase, which is critical to determine whether the patient's motivation is internal or external. Moreover, the drug addicts' trust in this treatment program is also investigated. The participant's interpersonal help seeking tendency is also evaluated to indicate the patient's need for social support.

These evaluations allow the effect of drug addicts' treatment motivation levels on compliance with treatment to be perceived. Moreover, this study aims to detect the deficiencies and the effectiveness of treatment programs, applied within the context of Supervised Release, to stop drug addicts using drugs.

\section{Method}

The process for patients sent to substance abuse treatment according to the requirements of Supervised Release is as follows: In the first stage of the free treatment program, patients must give weekly urine tests for three weeks. Patients who fail to provide drug-free urine samples at the hospital are required to participate in a six-week "Supervised Release Caution Substance Abuse Program." Once a week during the six weeks, these patients have to go to the hospital for a urine test and participate in a 90-minute psychoeducation group program where they attend a treatment program called Smoke, Alcohol, and Substance Abuse for Clinical Supervised Release Practice (SAMBA KDS). A report of compliance is prepared for the patients who adhere to the treatment and whose last three urine test results are negative. Patients who violate the rules are transferred to the Alcohol and Substance Addiction Treatment Center (AMATEM) as the third stage of treatment (The Ministry of Health of Turkey Circular, Sağllk Bakanlı̆̆l, 2015).

This study uses a questionnaire as a quantitative research method. The research sample consists of 112 patients who were sent to the Ministry of Health, Sakarya University Training and Research Hospital, Psychiatry Clinic by forensic units in Turkey within the context of a Supervised Release Program between the years 2012-2014. The participants were chosen among the patients referred to the six-week treatment and follow-up program because they failed to provide drug-free urine samples for three weeks. The researchers and the findings administered the research instruments were analyzed using the SPSS program (version 18, Chicago, USA).

After conducting the questionnaire at the beginning phase of the research, the participants started their treatment. All the participants completed the six-week treatment program. At the end of the study, it was established whether the patients continued to abuse substances during the six-week program or not. Within the scope of the treatment program, the Ministry of Health Circular (mandates) (2009) studies including the following subjects and topics were conducted during the six weeks: (1) informing about Supervised Release and addiction;(2) drugs and their effects; (3) increasing motivation; (4) the cycle of emotions, thoughts, and attitudes; (5) preventing drug use (preventing a relapse); and (6) recovery.

\section{Data Collection Tools}

\section{The Treatment Motivation Questionnaire (TMQ).}

This study employed a questionnaire developed by Ryan et al. (1995) to examine the reasons for participating in alcohol and substance addiction treatment. This questionnaire is designed as a Likert-type scale consisting of 26 items. The translation and validity and reliability studies of TMO were conducted by Evren et al. (2006). The original developers of the scale made factor and substance analyses for alcohol and substance treatment. According to factor analysis, the scale included the following four factors: internal motivation, external motivation, interpersonal help 
seeking, and trust in treatment. The factor structure of the Turkish version of the scale complies with the original scale (Evren et al., 2006). In this study, reliability analysis of the scale was conducted with the 112 out-patient drug addicts who attended a psychiatry clinic. The alpha reliability coefficient of the scale was 0.854 , which was considerably high for a reliability study. According to the results, all items of the scale are evaluated, and it seemed that items were reliable and valid. Considering these satisfactory results, the Turkish form of the scale is a valid and reliable instrument that can be applied to substance abusers. Moreover, seven demographic questions were added to identify the participants' characteristics. The intervals of the scale are as follows:1-2.60 points indicate a low level of motivation, 2.61-3.40 indicate a medium level of motivation, and 3.41-5indicate a high level of motivation.

\section{Data Analysis}

Data were analyzed using SPSS 18 statistics program. A normality test of the data was conducted and found that the data set indicates a normal distribution. Parametric tests were also employed in this study. Linear regression analysis was performed to identify the effect of treatment motivation on substance abuse. The general average means of four dimensions of the scale were calculated to identify the differences among the participants. Moreover, the substance abuse levels were identified using the Chi-Square test according to low, medium, and high treatment motivation levels.

\section{Findings}

\section{Socio-Demographic Findings}

All the participants were male, $58 \%$ of whom were single, $42 \%$ were married and primary school graduates. Of the participants, $42 \%$ were primary school graduates, and $6.3 \%$ were university graduates. Of the participants,
$37.5 \%$ were aged $18-25$ and $13.4 \%$ were over 46 years of age, $51.8 \%$ started using drugs aged $18-25$ and $0.9 \%$ started after the age of 46. Regarding their life situation, $80 \%$ of the participants were employed, and $53.6 \%$ had been imprisoned for drug traffic, causing injury, robbery, murder, prostitution, and causing damage to others' properties. It was observed that the characteristics of this sample were very similar to those reported by other previous studies elsewhere.

Table 1

General Average of Motivation

\begin{tabular}{lrr}
\hline \multicolumn{1}{c}{ Motivation Levels } & \multicolumn{1}{c}{ Means } & Standard Error \\
\hline Internal Motivation & 3.62 & 0.88 \\
External Motivation & 3.41 & 0.81 \\
Interpersonal Help Seeking & 2.67 & 0.81 \\
Trust in Treatment & 2.34 & 0.63 \\
\hline Total Motivation & 3.09 & 0.55 \\
\hline
\end{tabular}

Note. Mean ranged from 0 to 5

The participants' motivation levels were analyzed at the start-up phase. The highest motivation level was found to be internal motivation. Although the internal and external motivation levels of all participants were high, the interpersonal help seeking and trust in treatment tendencies were comparatively low. Based on the intervals of the scale presented in the Data Collection Tools section, all the participants started treatment with a mediumlevel motivation (average 3.09). The minimum and maximum treatment motivation levels were between 0 and 5 .

\section{Table 2}

Relationship between Treatment Motivation Levels and Substance Abuse

\begin{tabular}{llrrrrr}
\hline \multicolumn{1}{c}{ Treatment Motivation Level } & 1 & 2 & 3 & 4 & 5 \\
\hline 1. Substance abuse according to the testing & 1 & & & & \\
2. Internal motivation level & 0.014 & 1 & & & \\
3. External motivation level & 0.037 & $0.33^{* *}$ & 1 & & \\
4. Interpersonal help seeking & -0.09 & $0.48^{* *}$ & 0.16 & 1 & \\
5. & Mistrust in Treatment & -0.16 & 0.07 & 0.10 & 0.07 & 1 \\
\hline
\end{tabular}

$$
\text { ** Correlation is significant }
$$
at the 0.01 level (2-tailed).

According to the results of the correlation analysis (Table 2), a medium-level positive relationship (33\%) was found between external motivation and internal motivation. Therefore, an 
The Effect of Treatment Motivation Levels on Patients Sent to a Conditional Substance Abuse...

increase or decrease in one motivation type affects the other motivation type in the same way. A strong positive relationship (48\%) was found between interpersonal help seeking and internal motivation. However, no significant relationship exists between the treatment motivation levels and substance abuse. The effect of treatment motivation level on substance abuse is analyzed in the following table using regression analysis. The correlation is calculated with SPSS program. The degree of correlation is considered as; 0.00 to 0.30 low, 0.31 to 0.45 medium and 0.46 to 1.00 strong.

\section{Table 3}

Effect of Treatment Motivation Level on Substance Abuse

\begin{tabular}{lrrrrrr}
\hline \multicolumn{1}{c}{ Variable } & $\mathrm{B}$ & $\begin{array}{c}\text { Standard } \\
\text { Error B }\end{array}$ & $\beta$ & \multicolumn{1}{c}{$t$} & \multicolumn{1}{c}{$p$} & $\mathrm{R}^{2}$ \\
\hline Constant & 2.27 & 0.48 & & 4.68 & $0.00^{* *}$ & \\
Internal Motivation & -0.22 & 0.17 & -0.33 & -1.29 & 0.21 & 0.11 \\
Constant & 1.62 & 0.25 & & 6.4 & 0.00 & \\
External Motivation & -0.009 & 0.1 & -0.012 & -0.08 & 0.93 & 0.04 \\
Constant & 1.66 & 0.23 & & 7.11 & 0.00 & \\
Interpersonal Help Seeking & -0.047 & 0.12 & -0.07 & -0.37 & 0.71 & 0.005 \\
Constant & 1.86 & 0.18 & & 10 & 0.00 & \\
Trust in Treatment & -0.15 & 0.09 & -0.16 & -1.62 & 0.10 & 0.02 \\
\hline \multicolumn{7}{c}{ Note.Constant .00** (p < 0.01} \\
\\
High statistical significance)
\end{tabular}

The results of the regression analysis, conducted to identify the effect of treatment motivation levels on substance abuse (Table $3)$, indicated that internal motivation has a statistically significant effect on substance abuse. Considering the beta value, this effect is negative at the rate of $33 \%$. According to this result, internal motivation has a reducing effect on substance abuse. Similarly, external motivation has a small negative effect $(r=.012)$ on substance abuse. External motivation has a low, reducing effect on substance abuse Interpersonal helpseeking has a low negative effect $(\mathrm{r}=.07)$ on substance abuse, and trust in treatment has a negative effect $(\mathrm{r}=.16)$ on substance abuse.
Table 4

Substance Abuse Case and Different Levels of Motivation

\begin{tabular}{|c|c|c|c|c|c|}
\hline Motivation level & $\begin{array}{l}\text { According to Test } \\
\text { Result, Substance }\end{array}$ & $\mathrm{N}$ & Mean & $\begin{array}{l}\text { Std. } \\
\text { Error }\end{array}$ & $p$ \\
\hline \multirow{2}{*}{ Internal Motivation Level } & Used & $47(42 \%)$ & 3.68 & 0.81 & \multirow[t]{2}{*}{0.58} \\
\hline & Not Used & $65(5$ & 3.57 & 0.93 & \\
\hline \multirow{2}{*}{ External Motivation Level } & Used & $47(42 \%)$ & 3.41 & 0.81 & \multirow[t]{2}{*}{0.9} \\
\hline & Not Us & $65(5$ & 3.4 & 0.81 & \\
\hline \multirow{2}{*}{ Interpersonal Help Seeking } & Used & $47(42 \%)$ & 2.75 & 0.89 & \multirow[t]{2}{*}{0.41} \\
\hline & Not Used & $65(58 \%)$ & 2.61 & 0.75 & \\
\hline \multirow{2}{*}{ Trust in Treatment } & Used & $47(42 \%)$ & 2.22 & 0.70 & \multirow[t]{2}{*}{0.11} \\
\hline & Not Used & $65(58 \%)$ & 2.42 & 0.57 & \\
\hline
\end{tabular}

$p>0.05$ not statistically significant and averages ranged from 0 to 5 .

According to the test results, after all the participants (112) had completed the program, $65(58 \%)$ of the addicts refrained from substance abuse during the six-week program and therefore accomplished the treatment; therefore, 47 (42\%) of the participants had used substances and subsequently failed the treatment. According to the result of an independent samples t-test conducted to identify the difference between the motivation levels of those who took drugs and those who refrained from taking drugs during the program, a significant difference was not evident between internal and external motivation levels of the two groups of participants, and these motivation levels were high for each group. Moreover, no significant difference was found between interpersonal help seeking (medium level) and trust in treatment (low level) tendencies of participants for drug users/nonusers.

\section{Table 5}

Cross-Matching of Treatment Motivation Scale's Total Points and Sub-Factor Points with Substance Abuse Behaviors

\begin{tabular}{lrrr}
\hline \multicolumn{1}{c}{ Motivation } & $\begin{array}{c}\text { Substance } \\
\text { Used }\end{array}$ & $\begin{array}{c}\text { Substance } \\
\text { Not-Used }\end{array}$ & \multicolumn{1}{c}{ Total } \\
\hline Low Level of İnternal Motivation & 3 & 6 & $9(8 \%)$ \\
Middle Level of İnternal Motivation & 16 & 19 & $35(31.2 \%)$ \\
High Level of İnternal Motivation & 28 & 40 & $68(60.7 \%)$ \\
Total & 47 & 65 & 112 \\
\hline Low Level of External Motivation & 4 & 7 & $11(9.8 \%)$ \\
Middle Level of External Motivation & 9 & 20 & $39(34.8 \%)$ \\
High Level of External Motivation & 24 & 38 & $62(55.3 \%)$ \\
Total & 47 & 65 & 112 \\
\hline Low Level of İnterpersonal Help Seeking & 18 & 30 & $48(42.8 \%)$ \\
Middle Level of İnterpersonal Help Seeking & 20 & 27 & $47(41.9 \%)$ \\
High Level of Interpersonal Help Seeking & 9 & 8 & $17(15.1 \%)$ \\
Total & 47 & 65 & 112 \\
\hline Low Level of Trust to Treatment & 8 & 3 & $11(9.8 \%)$ \\
Middle Level of Trust to Treatment & 20 & 30 & $50(44.6 \%)$ \\
High Level of Trust to Treatment & 19 & 32 & $51(45.5 \%)$ \\
Total & 47 & 65 & 112 \\
\hline
\end{tabular}

A Chi-square test was conducted to identify the relationship between treatment motivation 
and substance abuse. The results were divided into three levels of treatment motivation: high, medium, and low. The value ranges of the scale are provided in the section entitled Data Collection Tools. Participant motivation levels were cross-matched according to the cases of participants who used drugs and did not use drugs during the six-week program. The results were as follows:

The relationship between internal motivation levels and substance abuse. It was found that $60.7 \%$ of the participants had high internal motivation, $31.2 \%$ had medium internal motivation, and $8 \%$ had low internal motivation. Notably, $58.8 \%$ of the participants with high internal motivation did not use drugs during the six-week treatment program.

The relationship between external motivation levels and substance abuse. It was found that $55.3 \%$ of participants had a high external motivation, $34.8 \%$ had medium, and $9.8 \%$ had low external motivation. Additionally, $61 \%$ of the participants with high internal motivation did not use drugs, while $37.8 \%$ of the participants used drugs at least once during the six-week treatment program.

The relationship between interpersonal help seeking and substance abuse. It was observed that $42.8 \%$ of participants' interpersonal help seeking was low, $41.9 \%$ was medium, and $15 \%$ was high. In response to the items, "It is important to work closely with others during treatment" and "I want to stay with others during [the] program," $59 \%$ and $89 \%$ of the participants answered "no", respectively. At the end of the six-week program, it was found that $37.5 \%$ of participants with low interpersonal help seeking used drugs and therefore failed the treatment.

The relationship between trust in treatment and substance abuse. It was revealed that $45.5 \%$ of participants had high trust in treatment, $44.6 \%$ had a medium level, and $9.8 \%$ did not trust in the treatment. It was concluded that $72.7 \%$ of participants who did not trust in the treatment and $37.2 \%$ of the participants who highly trusted in the treatment used drugs.

\section{Discussion}

A patient's motivation to change is complex and based on internal and external forces (Laudet \& Stanick, 2010). The substance abusers who participated in this current treatment program had medium-level treatment motivation at the start of the program. It was also observed that the participants with high initial treatment motivation, have lowered their substance abuse and increased their compliance with the treatment during the program. Client's motivation for change is a dynamic, multi-dimensional construct that represents an individual's openness and readiness for behavior change (Miller, 1999).

The more the participants' internal motivation and trust in treatment increased, the more their substance abuse decreased. External motivation and interpersonal help seeking have a reducing effect on substance abuse, but their effect is lower than the other factors. Moreover, there is a strong positive relationship between internal motivation and external motivation; and interpersonal help seeking and internal motivation. That is, any increase and decrease in each motivation type affects the other type.

According to existing literature, internal motivation has a greater increasing effect on the success of the treatment than external motivation during substance abuse treatment (Altintoprak et al., 2014). Ryan et al. (1995) stated that internal and external motivation ensures a positive treatment process. According to current findings, the participants with high internal motivation and the participants who had high trust in treatment had a lower substance abuse rate and their compliance with the treatment was better than the others who had an external motivation and low trust in treatment. Having an external motivation and interpersonal help seeking had less effect on the successful completion of substance abuse treatment program.

Therefore, it was considered that internal motivation sources such as readiness or treatment increase treatment success more than external motivation sources such as a court order. If clients' own initiative and motivation initiate 
the behavioral change, it last longer (Tsemberis, Gulcur \& Nakae, 2004).

Surprisingly, some participants had high treatment motivation during the start-up phase; however, they continued using drugs during the program and failed the treatment. Moreover, some participants, who did not consider themselves addicts, continued using drugs during the treatment program. These cases indicate that factors other than treatment motivation affect the success of the treatment. Possible factors include (1) treatment motivation levels of participants differ in various phases of the program, (2) some participants cannot stop using drugs due to overdependence, even if they have high motivation, (3) there are some problems and concerns about the effectiveness of the treatment program and the people who run and operate it, and (4) although some participants lacked treatment motivation, they were motivated by their fear of punishment of court systems and therefore; they did not use any substance during the treatment period.

Similar results were also reported by Ryan et al. (1995) study that internalized motivation is significantly negatively related to external motivation but positively related with interpersonal help-seeking and confidence in treatment. External motivation is negatively correlated with help seeking and confidence in treatment.

Zeldman, Ryan and Fisella's (2004) study, internally motivated individuals had lower relapse rates and better attendance, whereas people externally motivated for treatment had higher relapse rates and poor attendance. Selfdetermination theory offers that high-internal and low-external motivation leads to greater persistence and adherence (Zeldman, Ryan \& Fisella, 2004). On the other hand, Ryan et al. (1995) the study reported best results with alcohol abusers with the presence of both highinternal and high external motivation cases.

Considering these assumptions, the efficiency (effectiveness) of the treatment program run in public institutions and the judicial mechanism should be carefully examined. Freyer et al. (2005) defined readiness for change and readiness for help-seeking in two different concepts. Readiness for change is an important future and a good predictor of absenteeism. People who are determined to quit drinking, often do it themselves and do not seek formal help. However, people in treatment settings are not always motivated by their own decisions, court, employers or spouses face them. Perceived selfefficacy, life experiences and social support positively affect patient's readiness to change.

Loneliness and social withdrawal are commonly seen in substance abusers (Yildirım, Engin, \& Y1ldirım, 2011). Besides, therapist and hospital stuff, significant people in client's life can have a strong influence on clients' motivation. Individuals life settings and conditions play an important role in treatment. Significant others can provide help, feedback, and emotional support for change (Miller, Benefield \& Tonigan, 1993). There are also gender differences in motivation. Partner's pressures did not motivate men's. On the other hand, for women partner pressure was effective for the desire for help and treatment readiness (Riehman, Hser \& Zeller, 2000). Since all the participants were male, we were not able to detect gender differences in this study. However, spouses' help and understanding are always important and necessary for the success of treatment.

Friends' support for abstinence also helps with the success of recovery. This is especially true for men. Being around clean, normal peers is important for their sobriety. In clinical practice, counselors should encourage clients to establish a new friendship circle, including 12 -steps members and stay away from the old friendship culture. In the etiology of drug abuse, many patients report a poor and unsatisfactory relationship with their social and family relations (Bell, Atkinson, Williams, Nelson, \& Spence, 1996). Therefore, they might never learn to establish and maintain a mutual relationship. Clients who learn how to function in counseling settings, they can generalize those new skills in real life situations (Laudet \& Stanick, 2010).

This study also found that participants' motivation for social support and attending group studies was low and shown by the $89 \%$ of patients 
who answered "no" to the item: "I want to stay with others during the program." However, as this treatment program is conducted in a grouppsycho education format, using the SAMBA program has minimal therapeutic effects on a person's recovery from substance abuse. However, there are other programs specially designed for an aftercare program which are reported to be very effective.

Twelve-step programs utilized aftercare treatment options for both drug and alcohol abuse. Fiorentine's (1999) 24-month longitudinal studies revealed that 12-step programs are indeed effective and provided the patient's weekly or more frequent participation. However, participation less than was not effective, but it was better than nothing. It seems that social support is an important factor in treatment.

In another longitudinal study involving all male veterans, (McKellar, Stewart \& Humphreys, 2003) investigated the effectiveness of AA participation. Participation in AA groups helped to decrease alcohol consumption and related problems. Especially, higher involvement in AA groups first year, predicts second years' sobriety. Therefore, during the initial sessions, a nurturing relationship has a vital effect on motivation. Because, motivation fluctuates over the time and clients may often need affirmation, support and approval. Authors recommended to develop techniques of 12-Step oriented treatment programs and gave cognitive-behavioral self-help groups and SMART Recovery programs as a good example for secular organizations for maintaining sobriety.

Limitation of this type of programs could be, participants may not feel comfortable disclosing their personal information to a group, the spiritual content, and availability of groups may be an issue. However, whatever the case, mental health professionals should encourage their clients to participate aftercare, 12 steeps, alumni or similar type of social support groups. This is especially true for males. In cultures, such as Turkish one, manhood is characterized by a macho man to man relations. Thus, a male with substance abuse problems may need more normal, nondrinking male friends as such that they need to live in that friendship circle.

According to Ögel, Tamar, Evren, and Çakmak (2000), many difficulties and restrictions accompany questionnaires used in research related to substance abuse because drug addicts start the process by the decree of a court, and they witness that any procedure used in the hospital is reported, attendance for treatment is registered, and urine samples are given under the control of a police officer after a body search. This study experienced similar difficulties in administering the questionnaire because it is difficult to know whether the participants' answers about motivation are affected because of their judicial worries. It was also observed that participants did not trust in the treatment adequately. Because the participants did not consider themselves addicts; thus when they start the treatment because of a court order, they did not think that the program would be useful for themselves.

Previous literature highlights the relationship between substance abuse and socio-demographic attributes. According to these studies, the substance abuse rate is higher in young adults and males (Lo, 2004). Similarly, in this study, half of the participants started using drugs aged 18-25 and $0.9 \%$ of participants started at over 46 years of age. This indicates that the substance abuse rate decreases significantly with age. Regarding gender, all participants were male. No female participants were included in this study because very few women are put on Supervised Release. This is because women's substance abuse rate is pretty low in Turkish society. Additionally, in the first three-week control stage, women were more successful and therefore, very few women attended the six-week program.

Substance abusers may vary in their cognitive stage for change. Prochaska, DiClemente and Norcross (1992) proposed a 4-stage model which involves, contemplation, preparation, action, maintenance respectively. Those stages show how an abuser goes through those stages and how the recovery process functions. Therefore, it is important for mental health professionals to figure out patients' level of 
readiness and preparedness before they proceed with treatment.

Moreover, crime rates of substance abusers seem to be higher worldwide. There are some findings of that in Turkey (Ögel \& Aksoy, 2007). For instance, Bulut et al. (2006) found the crime rate of substance abusers is $52.2 \%$, which is similar to our finding of $53.6 \%$. According to previous reports on crime, rates other than substance abuse, and decreases with age. Substance abusers and narcotic addicts may be involved in other crimes (violence, traffic accidents, etc.) because of the influence or purchasing/selling of drugs (Fernandez et al., 2013). This situation is a risk factor, considered as a reason for crime, especially among the younger population.

\section{Suggestions}

Based on the data acquired in this study, treatment motivation of drug addicts in "Supervised Release Caution Substance Abuse Program" should always be kept high. Therefore, treatment motivation levels must be assessed at the beginning of the program. Participants should not feel any indication of official or legal process by health or legal personnel. It was observed that participants attending the treatment on Supervised Release were unwilling to attend the psycho-education groups voluntarily. SAMBA has been employed by The Ministry of Health and The Ministry of Justice for a long time, and it has become the official treatment and education program for both ministries. Therefore, the efficiency of this treatment program with a psycho-education group must be evaluated by scientific studies, and the short and long-term result must be published in the scientific arena.

Many people have to enter a treatment program because of external pressure from family members or judicial systems. Thus, this causes a challenge for the mental health professional to keep motivation and encourage them for behavioral change (Zeldman, Ryan \& Fiscella, 2004). In order to enhance motivation and persistence for treatment, Self Determination
Theory (Deci \& Ryan, 1985) suggests that addicts' feelings of autonomy which involves a sense of cheerfulness, authenticity and personal endorsement. In contrast, feeling controlled involves a sense of pressure and punishment. In fact, autonomy and control both lie in the same spectrum. Most individuals show mixed motives. Some people experience both autonomous and controlled sources of motivation simultaneously.

Current AMATEM implementations and practices are widely criticized because participants who are heavily addicted to drugs and participants who have addictive tendencies are treated in the same place with the same methods. This situation causes new patients to be more affected by those with chronic substance abusers (Psychiatric Association of Turkey, 2008). The researchers and academicians who made this criticism and contributed to the "Supervised Release Caution Substance Abuse Program" did not realize that the mistake made in AMATEM is also valid for the Supervised Release Program because the "Supervised Release Caution Substance Abuse Program" not only identifies the substance abusers but also tries to treat any kind of addiction. Thus, participants who do not know each other before the program meet on the program and continue to communicate outside of the hospital. This situation could lead to new patients being influenced by heavily addicted patients, and thus decreasing their motivation levels. Drug procurement could also become easier, as in the case of AMATEM. At this point, it seems that social support is important and influences factor for clients to start the treatment, stay in treatment and keep clean even after the treatment.

Sobell \& Sobell (2000) recommended less restrictive and brief models as a more effective treatment model. The clinical settings also vary in their treatment approaches encouraging autonomous self-regulation versus controlling patients' behavior. Autonomysupportive approaches and settings encourage the clients to take responsibility for their change and help people understand the rationale for treatment (Ryan et al., 1995). As such that 
when patients feel, they are being listened, given options and accepted, then this reflects better adherence and sobriety. The greater perceived the autonomy support from clinical staff, the lower the relapse and less missed appointments (Zeldman, Ryan \& Fisella, 2004). In clinical settings, the client's education, employment, and housing needs should be considered (Laudet, Stanick \& Sands, 2009). Intervention strategies should be modified according to the client's needs, strengths and aspirations. Clinics and treatment settings can provide a more autonomysupportive environment by allowing their clients to take a more active role in their treatment plan and paying attention social and emotional needs (Zeldman, Ryan \& Fisella, 2004).

The difference between the numbers of people in need of treatment and people receiving treatment is increasing day by day; thus, new approaches for the treatment are required. Technology supported interventions in substance-use disorders play an important role in increasing the accessibility of treatment. This method makes treatment easier to access, especially for parents and women who have difficulties attending treatment because of housework or childcare (VanDeMark et al., 2010). In recent years, distance psychological therapy (online therapy), which is a new trend, has attracted attention as a new approach for carrying out follow-ups and increasing the rate of applications for alcohol and substance treatment (Bozkurt, 2013). Follow-up care is important in preventing recurrences in the current treatment approach of drug dependency. Furthermore, psychological follow-up care by phone and other technological devices can meet this need (McLellan, 2002).

In countries that have call centers for drug dependents, $76.6 \%$ of callers are new substance abusers, indicating the importance of prevention and treatment of addiction (Türkcan et al., 2001). Similarly, alcoholics and drug addicts want to remain anonymous. Therefore, reading books and other written materials, known as "bibliotherapy," should be integrated into the treatment program to accelerate the treatment process. These methods help addicts to change their defensive attitudes, accept treatment, and increase their motivation levels (Bulut, 2010) making it an effective method for treating substance abuse.

Based on these findings, researchers must concentrate on studies related to increasing treatment motivation at every stage of the treatment program to increase substance abusers' compliance with the treatment. Motivation is an important concept that determines entry commitment and staying in treatment. Furthermore, motivation is a dynamic process and sometimes fluctuates during the treatment (Reeve, 1992). Thus, mental health professionals should also pay attention to the client's needs during each step of a treatment program. Supportive therapeutic relationships improve client's engagement and retention in treatment (Joe, Simpson, Dansereau \& Rowan-Szal, 2001). Thus, an early therapeutic alliance is a very important factor. Regarding gender differences in therapeutic alliance, for females, caring was an important need and women seek more emphatic counseling styles whereas males seek helpfulness but not caring, and they prefer a more utilitarian style (Meier, Barrowclough \& Donmall, 2005). It is also argued that offenders who acknowledge their drug-related problems, establish stronger therapeutic relations with their counselors (Broome, Knight, Knight, Hiller \& Simpson, 1997).

As for the therapist style, non-confidential and non-provoking style were more effective than the challenging and confrontational approach. A therapist who was listening and restructuring were perceived as an ally and lead effective results. On the other hand, a confrontational approach does not lead a fruitful result (Miller, Benefield \& Tonigan, 1993). Moreover, it is imperative to make necessary changes to improve the effectiveness of Supervised Release treatment programs, which would help increase the success of the treatment. Correction and modification are needed to increase the success of these programs. Finally, the efficiency of the treatment methods applied in both the AMATEM and the "Supervised Release Caution Substance Abuse 
Program" underlying our study must be further investigated in detail.

In treatment planning, living accommodations should be carefully considered because people with severe alcohol problems are homeless or living in poor living conditions. Therefore, residential care can be required (Sobell \& Sobell, 2000). However, this "homelessness" phenomenon is not observed or well-known topic, thus, this was not applicable to this current study. In contrast to Western countries, homelessness is not an issue in Turkey. In a mandated residential substance abuse treatment program with felony probationers, older probationers showed great progress, whereas divorced, separated, and widowed showed less progress. Older patients and patients with partner benefit better. Feelings of psychological safety caused higher levels of help-seeking and treatment motivation. Female offenders reported more trust in treatment personnel and group members than male participants (Hiller, Knight, Leukefeld \& Simpson, 2002). However, in our current study, there were no female participants in the program.

Hiller, Knight, Leukefeld and Simpson (2002) utilized DCJTC model in correctional facilities, including group and individual counseling, behavior modifications, peer counseling, life skills training, vocational and educational instruction, regular meeting with parole officers emphasizing 12-steep recovery program, reviewing criminal thinking pattern, relapse prevention, confrontational groups and evening meetings. This model incorporates many therapeutic methods, guidance, and psychoeducational groups. Therefore, it looks like a more heuristic approach and can be usable in Turkey as well. The sample population of this current study seems to be similar to the previous study samples; as such that a great majority of participants are male, single, unemployed and have less than high school completion in terms of education status.

\section{References}

Altıntoprak, E. A., Akgür, A. S., Kitapçıŏlu, G., Yüncü, Z., \& Coşkunol, H. (2014). Retrospective analysis of probationers: sociodemographic characteristics, individual and familial history of addiction and crime, and treatment outcomes. Journal of Dependence, 15(1), 1-9.

Bates, M. E., Bowden, S. C., \& Barry, D. (2002). Neurocognitive impairment associated with alcohol use disorders: Implications for treatment. Experimental and Clinical Psychopharmacology, 10(3), 193-212. http://dx.doi.org/10.1037/1064-1 297.10.3.193

Bell, D. C., Atkinson, J. S., Williams, M. L., Nelson, R., \& Spence, R. T. (1996). The trajectory of client progress. A longitudinal pilot study. Journal of Substance Abuse Treatment, 13(3),211-218. https://doi.org/1 0.1016/S0740-5472(96)00046-3

Bozkurt, İ. (2013). The new trend in psychological support practices: Online therapies. International Journal of Human Sciences, 10(2), 130-146.

Broome, K. M., Knight, D. K., Knight, K., Hiller, M. L., \& Simpson, D. D. (1997). Peer, family, and motivational influences on drug treatment process and recidivism for probationers. Journal of Clinical Psychology, 53(4), 387-397. https://doi.org/10.1002/(SICI) 10 97-4679(199706)53:4\%3C387::AID-JCLP 12\%3E3.0.CO;2-C

Bulut, M., Savaş, A. H., Cansel, N., Selek, S., Kap, Ö., Yumru, M., \& Virit, O. (2006). Sociodemographic characteristics of patients, applied to substance usage disorders unit of Gaziantep University. Journal of Dependence, 7(2), 65-70.

Bulut, S. (2010). Using bibliotherapy in adult counseling. Turkish Psychological Counseling and Guidance Journal, 4(33), 46-56.

Cahill, M. A., Adinoff, B., Hosig, H., Muller, K., \& Pulliam, C. (2003). Motivation for treatment preceding and following 
a substance abuse program. Addictive Behaviors, 28(1), 67-79. https://doi.org/10.1 016/S0306-4603(01)00217-9

Çiftçi, G. E., \& Uluocak, P. G. (2010). Almanya'da madde bağımlısı çocuk ve gençlere yönelik bir rehabilitasyon modeli. Kriz Dergisi, 18(2), 11-18. Retrieved from http://dergiler.ankara.edu.tr/dergiler/ 21/1875/19686.pdf

Deci, E. L., \& Ryan, R. M. (1985). Intrinsic motivation and self-determination in human behavior. New York, NY: Plenum.

Erol, S., \& Erdoğan, S. (2007). Application of transtheoretic model for improving and changing health behaviours. Journal of Anatolia Nursing and Health Sciences, 10 (2), 86-94.

Evren, C., Dalbudak, E., \& Çakmak, D. (2008). Factorial structure and reliability and validity of Turkish version the stages of change readiness and treatment eagerness scale (SOCRATES) in male alcohol dependent inpatients. Bulletin of Clinical Psychopharmacology, 18(2), 84-91. Retrieved from https://www.researchgate.n et/publication/289311280_Factorial_struct ure_and_reliability_and_validity_of_Turki sh_version_the_Stages_of_Change_Readi ness_and_Treatment_Eagerness_Scale_S OCRATES_in_male_alcohol_dependent inpatients

Evren, C., Saatçioğlu, Ö., Dalbudak, E., Danışmant, B. S., Çakmak, D., \& Ryan, R. M. (2006). Tedavi motivasyonu anketi (TMA) Türkçe versiyonunun alkol bağımlısı hastalarda faktör yapısı, geçerliği ve güvenirliği. Bağımlllı Dergisi, 7(3), 117-122. [Factorial structure, reliability and validity of a Turkish version Treatment Motivation Questionnaire (TMQ) in alcohol dependents]. Journal of Dependence, 7 (3), 117-122

Fernandez-Montalvo, J., Lopez-Goni, J. J., Arteaga, A., \& Cacho, R. (2013). Criminological profile of patients in addiction treatment. Adicciones, 25(2), 146-155.
Fiorentine, R. (1999). After drug treatment: Are 12-step programs effective in maintaining abstinence? American Journal of Drug and Alcohol Abuse, 25(1), 93-116. https://doi.or g/10.1081/ADA-100101848

Freyer, J., Toningan, J. S., Keller, S., Rumpf, H. J., John, U., \& Hapke, U. (2005). Readiness for change and readiness for help seeking: A composite assessment of client motivation. Alcohol Eु Alcoholism, 40(6),540-544. https ://doi.org/10.1093/alcalc/agh195

Friedmann, P. D., Green, T. C., Taxman, F. S., Harrington, M., Rhodes, A. G., Katz, E., ... Fletcher, B. W.(2012). Collaborative behavioral management among parolees: drug use, crime and re-arrest in the step'n out randomized trial. British Journal of Addiction, 107(6), 1099-1108. https://doi.o $\mathrm{rg} / 10.1111 / \mathrm{j} .1360-0443.2011 .03769 . x$

Hiller, M. L., Knight, K., Leukefeld, C., \& Simpson, D.D. (2002). Motivation as a Predictor of Therapeutic Engagement in Mandated Residential Substance Abuse Treatment. Criminal Justice and Behavior, 29(1), 56-75. https://doi.org/10.1177/0093 854802029001004

Joe, G. W., Simpson, D. D., Dansereau, D. F., \& Rowan-Szal, G. A. (2001). Relationships between counseling rapport and drug abuse treatment outcomes. Psychiatric Services, 52 (9),1223-1229. https://doi.org/10.1176/a ppi.ps.52.9.1223

Laudet, A. B., \& Stanick, V. (2010). Predictors of motivation for abstinence at the end of outpatient substance abuse treatment. Journal of Substance Abuse Treatment, 38(4), 317-327. https://doi.org/10.1016/j.jsat.201 0.01 .007

Laudet, A. B., Stanick, V. \& Sands, B. (2009). What could the program have done differently? A qualitative examination of reasons for leaving outpatient treatment. Journal of Substance Abuse Treatment, 37(2),182-190. https://doi.org/10.1016/j.jsa t.2009.01.001

Lo, C. C. (2004). Sociodemographic factors, drug abuse, and other crimes: How they vary among male and female arrestees. Journal of 
The Effect of Treatment Motivation Levels on Patients Sent to a Conditional Substance Abuse...

Criminal Justice, 32(5), 399-409. https://doi .org/10.1016/j.jcrimjus.2004.06.002

McCollister, K. E., Scott, C. K., Dennis, M. L., Freitas, D. M., French, M. T., \& Funk, R. R. (2014). Economic costs of a post release intervention for incarcerated female substance abusers: Recovery management checkups for women offenders (RMC WO). Journal of Offender Rehabilitation, 53(7), 543-561. https://doi.org/10.1080/10 509674.2014 .944739

McKellar, J., Stewart, E., \& Humphreys, K. (2003). Alcoholics anonymous involvement and positive alcohol-related outcomes: Cause, consequences, or just a correlate? A prospective 2-year study of 2,319 alcohol dependent men. Journal of Consulting and Clinical Psychology, 71(2), 302-308. https://doi.org/10.1037/0022-006 X.71.2.302

McLellan, A. T. (2002). Have we evaluated addiction treatment correctly? Implications from a chronic care perspective. Addiction, 97(3), 249-252. https://doi.org/10.1046/j.1 360-0443.2002.00127.x

Meier, P. S., Barrowclough, C., \& Donmall, M. C. (2005). The role of the therapeutic alliance in the treatment of substance misuse: A critical review of the literature. Addiction, 100 (3), 304-316. http://dx.doi.org/10.1111 /j.1360-0443.2004.00935.x

Miller, W. R. (1999). Enhancing motivation for change in substance abuse treatment (TIP Series \# 35). Rockville, MD: US. Department of Health and Human Services, Center for Substance Abuse Treatment.

Miller, W. R., Benefield, R. G., \& Tonigan, J. S. (1993). Enhancing motivation for change in problem drinking: A controlled comparison of two therapist styles. Journal of Consulting and Clinical Psychology, 61(3), 455-461.

Ögel, K., \& Aksoy, A. (2007). Substance use in deliquent adolescents. Journal of Dependence, 8, 11-17.

Ögel, K., Koç, C., Aksoy, A., \& Yorohan, R. (2011). SAMBA: Sigara, alkol ve madde bağımlllığı tedavi programı geliştirilme süreci. 7.Ulusal Alkol ve Madde Bă̆rmlılı̆̆ Kongresi, poster sunumu, 08-11 Aralı, Antalya.

Ögel, K., Koç, C., Karalar, B., Başabak, A., Aksoy, A., İsmen, M \& Yeroham R. (2011). Effectiveness of an addiction treatment program called SAMBA: A pilot study. Bulletin of Clinical Psychopharmacology, $21(2), 150-151$.

Ögel, K., Tamar, D., Evren, C., \& Çakmak, D. (2000). İstanbul'da lise gençleri arasında sigara, alkol ve madde kullanım yaygınlığı. Klinik psikiyatri, 3(4), 242-345.

Özdemir, H., \& Taşc1, S. (2013). Motivasyonel görüşme tekniği ve hemşirelikte kullanimi- The application of motivational interviewing technique in nursing. ERÜ Sağllk Bilimleri Fakültesi Dergisi, 1(1), 41-47.

Prochaska, J. O., DiClemente, C. C. (1986). Toward a comprehensive model of change. In W. R. Miller, \& N. Heather (Eds.), Treating addictive behaviors (pp. 3-27). New York: Plenum.

Prochaska, J. O., DiClemente, C.C. \& Norcross. J. C. (1992). In search of how people change: Applications to addictive behaviors. American Psychologist, 47(9), 1102-1114.

Psychiatric Association of Turkey (2008). Supervised Substance Abuse Release Program Group Reports. Retrieved from http://www.psikiyatri.org.tr/upload.as px? upload $=333$ on August 14th, 2014.

Reeve, J. (1992). Understanding motivation and emotion. Sixth Eds. John Wiley \& Sons Inc., Hoboken, NJ. USA.

Riehman, K. S., Hser, Y., \& Zeller, M. (2000). Gender Differences in how intimate partners influence drug treatment motivation. Journal of Drug Issues, 30 (4), 823-838. https://doi.org/10.1177/00220426 0003000409

Ryan, R. M., Plant, R. W., \& O'Malley, S. (1995). Initial motivations for alcohol treatment: Relations with patient characteristics, treatment involvement, and dropout. 
Addictive Behaviors, 20(3), 279-297. https:/ /doi.org/10.1016/0306-4603(94)00072-7

Sağlık Bakanlığı. (2009). Denetimli serbestlik tedbirleri hizmetleri uygulanan kişilerin tedavileri hakkmda genelge. Retrieved from http://www.saglik.gov.tr/TR/dosya/1 53295/h/genelgeler.doc

Sağlık Bakanlığı. (2015). Denetimli serbestlik tedavi hizmetleri hakkında genelge. Retrieved from http://www.saglik.gov.tr/Hastahaklari /dosya/196339/h/denetimliserbestliktedavi hizmetlerigenelge-1.pdf

Savaşan, A. (2010). Bağımlılığı olan hastalarda servis ortamı ve tedavi motivasyonu ilişkisinin incelenmesi. Klinik Psikiyatri, 13, 119-126.

Simoneau, H., \& Bergeron, J. (2003). Factors affecting motivation during the first six weeks of treatment. Addictive Behaviors, 28(7), 1219-1241. https://doi.org/10.1016/ S0306-4603(02)00257-5

Sobell, M. B., \& Sobell, L. C. (2000). Stepped care as a heuristic approach to the treatment of alcohol problems. Journal of Consulting and Clinical Psychology, 68(4), 573-579. https://doi.org/10.1037//0022-00 6X.68.4.573

Türkcan, A., Yazman, Ü., Özgür, S., Korkut, A., Ertan, N., \& Çakmak, D. (2001). Alkol veya madde kullanımına ilişkin sorunlarda telefon ile danışma hattına başvuranların özellikleri ve hattın işlevselliği. Bağımlllk Dergisi, 2(1), 34-37.

Tsemberis, S., Gulcur, L., \& Nakae, M. (2004). Housing first, consumer choice and harm reduction for homeless individuals with a dual diagnosis. American Journal of Public Health, 94(4), 651-656. https://doi.org/10.2 105/AJPH.94.4.651

VanDeMark, N. R., Burrell, N. R., LaMendola, W. F., Hoich, C. A., Berg, N. P., \& Medina, E. (2010). An exploratory study of engagement in a technology-supported substance abuse intervention. Substance Abuse Treatment, Prevention, and Policy, 5(10), 5-10. https://doi.org/10.1186/1747-5 $97 \mathrm{X}-5-10$
Wild, C. T., Cunningham, J. A., \& Ryan, R. M. (2006). Social pressure, coercion, and client engagement at treatment entry: A self-determination theory perspective. Addictive Behaviors, 31 (10), 1858-1872. htt ps://doi.org/10.1016/j.addbeh.2006.01.002

Yavuz, H. A. (2012). Historical development of probation in the Turkish criminal justice. Union of Turkish Bar Assocations Review, 100(1), 317-342. Retrieved from http://tbbdergisi.barobirlik.org.tr/App $\overline{7}$

Themes/TumDergiler/100.pdf\# page $=31$

Yıldırım, B., Engin, E., \& Yıldırım, S. (2011). Loneliness and effective factors in alcohol and drug dependence. Journal of Psychiatric Nursing, 2(1), 25-30.

Zeldman, A., Ryan, R. M., \& Fiscella, K. (2004). Motivation, Autonomy Support, and Entity Beliefs: Their role in methadone maintenance treatment. Journal of Social and Clinical Psychology, 23(5), 675-696. htt ps://doi.org/10.1521/jscp.23.5.675.50744

\section{Notes}

* Research article. 